\title{
SCREENING, MORPHOLOGICAL AND MOLECULAR CHARACTERIZATION OF FUNGI PRODUCING CYSTATHIONINE $\gamma$-LYASE
}

\author{
Ashraf S. El-SaYed,${ }^{1 *}$ Salwa A. Khalaf, ${ }^{1}$ \\ GAmal ABDEL-HAmid ${ }^{2}$ and MoHAmed I. EL-BATRIK ${ }^{1}$ \\ ${ }^{1}$ Microbiology Department, Faculty of Science, Zagazig University, Zagazig, Egypt \\ ${ }^{2}$ Egyptian Atomic Energy Authority, Inshas, Cairo, Egypt \\ (Received: October 29, 2013; accepted: May 21, 2014)
}

\begin{abstract}
The potency for production of cystathionine $\gamma$-lyase (CGL) by the fungal isolates was screened. Among the tested twenty-two isolates, Aspergillus carneus was the potent CGL producer $(6.29 \mathrm{U} / \mathrm{mg})$, followed by A. ochraceous (6.03 U/mg), A. versicolor (2.51 U/mg), A. candidus (2.12 U/mg), A. niveus and Penicillium notatum $(2.0 \mathrm{U} / \mathrm{mg})$. The potent six isolates producing CGL was characterized morphologically, A. carneus KF723837 was further molecularly characterized based on the sequence of 18S-28S rDNA. Upon sulfur starvation, the yield of A. carneus extracellular CGL was increased by about 1.7- and 4.1-fold comparing to non-sulfur starved and L-methionine free medium, respectively. Also, the uptake of L-methionine was duplicated upon sulfur starvation, assuming the activation of specific transporters for L-methionine and efflux of CGL. Also, the intracellular thiols and GDH activity of A. carneus was strongly increased by $\mathrm{S}$ starvation, revealing the activation of in vivo metabolic antioxidant systems. Upon irradiation of $A$. carneus by $2.0 \mathrm{kGy}$ of $\gamma$-rays, the activity of CGL was increased by two-fold, regarding to control, with an obvious decreases on its yield upon further doses. Practically, CGL activity from the solid A. carneus cultures, using rice bran as substrate, was increased by 1.2 -fold, comparing to submerged cultures, under optimum conditions.
\end{abstract}

Keywords: Aspergillus carneus - cystathionine $\gamma$-lyase - morphological - molecular analysis

\section{INTRODUCTION}

Cystathionine $\gamma$-lyase (CGL; E.C. 4.4.1.1) is a pyridoxal 5-phosphate (PLP) dependent enzyme, catalyzing the $\gamma$-elimination of cystathionine to cysteine, $\alpha$-ketobutyrate and ammonia [39]. CGL and cystathionine $\beta$-lyase (CBL) are the main PLPdependent enzymes of methionine-cysteine cycle, via transsulfuration and reverse transsulfuration pathways [30]. CGL has been received much attention for its therapeutic applications against various diseases related to cystathioninuria as developmental delay, thrompocytopenia, diabetes and cystic fibrosis [20, 26, 41, 49]. Biochemically, cystathioninuria is a hyper-accumulation of cystathionine due to the malfunctions of CGL and CBL or deficiency of their co-enzyme PLP [49] that is correlated with homocysteinuria [34]. Thus, both clinical disorders could be correlated

*Corresponding author; e-mail address: ash.elsayed@gmail.com 
with acute deficiencies of vitamins $\mathrm{B}_{6}, \mathrm{~B}_{12}$ and folic acid as co-enzymes for L-methionine cycle enzymes [16]. However, the main cause of cystathioninuria is the lack in genetical expression of CGL in human tissues [26, 38]. Also, CGL was implicated in generating of endogenous $\mathrm{H}_{2} \mathrm{~S}$ as essential gasotransmitters for membrane hyper-polarization and smooth muscle cell relaxation [50, 51]. CGL has been extensively characterized in various bacterial genera as Lactococcus [5, 30], Lactobacillus $[8,47]$ and Streptomyces [39]. However, the CGL activity was detected in various fungal isolates as $N$. crassa, Sac. cerevisiae [9, 29], A. nidulans [40], C. acremonium [22], G. candidum [25]. Unlike the numerous biochemical studies to bacterial CGL, scarcely reports on this enzyme from fungi, the structural and catalytic properties of the fungal CGL has remained vague. Practically, the higher potency of fungi for growth and enzyme production under solid state fermentation (SSF), using natural agricultural wastes as substrates is an affordable physiological criterion [16].

Therefore, the current study was a preliminary screening for CGL production from local filamentous fungal isolates. The morphological and molecular properties of the most potent fungal isolates producing CGL were characterized. Maximization of the enzyme yield upon sulfur starvation and $\gamma$-irradiation by the fungal isolate was also studied.

\section{MATERIALS AND METHODS}

\section{Materials}

L-Cystathionine, L-methionine, L-cysteine, pyridoxal 5'-phosphate (PLP), 5,5'-dithiobis (2-nitrobenzoic acid) (DTNB) were purchased from Sigma-Aldrich Co. (Spruce, St. Louis, MO, USA). All the other chemicals were of analytical grade. Rice bran, as solid substrates was obtained from local Egyptian markets.

\section{Fungal cultures and screening for cystathionine $\gamma$-lyase production}

Twenty-two fungal isolates, as lab stock [14, 18], were screened for production CGL on L-methionine-glucose medium [32], as follows; L-methionine (0.5\%), glucose $(0.1 \%), \mathrm{K}_{2} \mathrm{HPO}_{4}(0.2 \%), \mathrm{MgSO}_{4} \cdot 7 \mathrm{H}_{2} \mathrm{O}(0.05 \%)$ and $\mathrm{KCl}(0.05 \%)$, dissolved in tap water ( $\mathrm{pH} 7.0)$. After 7 days of incubation at $30{ }^{\circ} \mathrm{C}$ on shaker incubator $(130 \mathrm{rpm})$, the cultures were filtered and the crude intracellular and extracellular CGL was prepared [14]. Biological triplicates of each sample were prepared. The activity and concentration of CGL was assessed.

\section{Cystathionine $\gamma$-lyase assay}

The activity of CGL was assessed based on the amount of released cysteine by DTNB assay [48]. The reaction mixture contains; L-cystathionine $(20 \mathrm{mM})$ in potassium 
phosphate buffer pH 7.5, PLP $(20 \mu \mathrm{M})$, DTNB $(250 \mu \mathrm{M})$ and enzyme preparation in a total volume $1.0 \mathrm{ml}$. Enzyme and substrate blanks were prepared. The reaction mixture was incubated at $40{ }^{\circ} \mathrm{C}$, for $15 \mathrm{~min}$, the developed yellow color was measured at $412 \mathrm{~nm}$, against authentic cysteine concentrations $(10-100 \mu \mathrm{M})$. One unit (U) of CGL was expressed by the amount of enzyme which released $1 \mu \mathrm{M}$ of cysteine per min under optimal assay conditions. Specific activity was represented by the mean of CGL activity (U) per mg of enzyme protein.

\section{Protein concentration}

The CGL concentration was determined by Folin's reagent [36], using bovine serum albumin as authentic.

\section{Morphological and molecular characterizations of CGL producing fungi}

\section{Morphological characterization}

The morphological features of CGL producing fungi were extensively characterized based on the universally accepted keys of fungal identification [3, 13, 42, 44, 45]. The potent isolates producing CGL were further characterized molecularly.

\section{Molecular characterization}

Genomic DNA extraction. The molecular characterization of the potent isolates was conducted based on the sequence of rDNA [14]. Briefly, $0.2 \mathrm{~g}$ of the mycelia was vigorously homogenized in liquid nitrogen for $10 \mathrm{~min}$, addition of $500 \mu \mathrm{l}$ of DNA extraction buffer (200 mM Tris-HCl, pH 8.0, $240 \mathrm{mM} \mathrm{NaCl}, 25 \mathrm{mM}$ EDTA, and 1\% SDS), in Eppe tube, vortex and centrifuge for $5 \mathrm{~min}$ at 10,000 rpm. The supernatant was gently mixed with equal volume of phenol: chloroform $(1: 1 \mathrm{v} / \mathrm{v})$ for $30 \mathrm{~min}$, then centrifuged at $12,000 \mathrm{rpm}$. The upper phase was gently withdrawn and mixed with equal volume of $96 \%$ ethanol for $60 \mathrm{~min}$ at $-20^{\circ} \mathrm{C}$. After centrifugation, the collected DNA pellets were washed in $70 \%$ ethanol, dried, and re-suspended in $50 \mu 1$ of double distilled water.

$P C R$ amplification. The fungal isolate was identified based on its whole sequence of rDNA by $18 \mathrm{~S}-28 \mathrm{~S}$ rDNA, this sequence flanks the ITS 1, 5.8S rRNA, and ITS 2 sequence. Two sets of primers were used: Fw 18s rRNA 5'-GTAACAAGGTTTCCGTAGGT-3', Rev 28s rRNA 5'-TTGATATGCTTAAGTTCGGCCG-3'. The PCR reaction contained about $10 \mathrm{mg}$ DNA, $5 \mu \mathrm{l}$ of $10 \times$ reaction buffer, $1.25 \mathrm{U}$ Taq polymerase, $200 \mu \mathrm{M}$ dNTP and $200 \mu \mathrm{M}$ of each primer in a $50 \mu \mathrm{l}$ total volume. The designed PCR protocol included 35 cycles of denaturation at $95^{\circ} \mathrm{C}$ for $30 \mathrm{~s}$, annealing at $56{ }^{\circ} \mathrm{C}$ for $30 \mathrm{~s}$, and elongation at $72{ }^{\circ} \mathrm{C}$ for $1 \mathrm{~min}$. The PCR product was 
resolved using $0.8 \%$ agarose gel, then purified using a PCR purification kit (Fermentas, Germany) prior to DNA sequencing (ABI 377 DNA Autosequencer, PerkinElmer, Applied Biosystems Div. Waltham, MA, USA) using the same above primers. The retrieved sequence (18s-28s rDNA) was deposited in the GenBank. Using various softwares (http://www.genome.HP/tools/.clustals), the relatedness of the retrieved sequence for the fungal isolate was constructed.

\section{Fermentation conditions for production of CGL}

Production of CGL was explored by both submerged and solid state fermented cultures by the potent fungal isolate. CGL production by the submerged fermented fungal cultures was conducted, using L-methionine-glucose medium as mentioned above. After incubation, the cultures were filtered, the crude intra and extracellular CGL was prepared, and their activity was assessed as described above.

CGL production by the potent isolate under solid state fermentation was evaluated, using rice bran that was selected as solid substrate based on our previous studies [15, 17]. The SSF medium contains: $5 \mathrm{~g}$ of air dried rice bran dispensed in $250 \mathrm{ml}$ Erlenmeyer conical flasks, autoclaved, then amended with $20 \mathrm{ml}$ sterile salt solution (glucose $0.5 \%, \mathrm{~K}_{2} \mathrm{HPO}_{4} 0.2 \%, \mathrm{MgSO}_{4}, 7 \mathrm{H}_{2} \mathrm{O} 0.05 \%$ and $\mathrm{KCl} 0.05 \%$ dissolved in tap water $\mathrm{pH}$ 7.0) [14]. The medium was inoculated by the spore suspension of tested fungal isolate $\left(2 \mathrm{ml} / 5 \mathrm{~g}\right.$ solid substrate), incubated for 8 days at $30^{\circ} \mathrm{C}$. After incubation, the crude CGL from the SSF cultures was extracted by potassium phosphate buffer [14]. The extracted enzyme was repeatedly clarified by centrifugation $(5000$ $\mathrm{rpm}, 10 \mathrm{~min}$ ) then its yield was determined as above.

\section{RESULTS AND DISCUSSION}

\section{Screening for CGL production by fungi}

Twenty-two fungal isolates as stock cultures of our lab were screened for CGL production on L-methionine-glucose medium [14, 32]. From the screening profile (Table 1), all the fungal isolates have the potency for production of extracellular CGL, with reliable fluctuation. The maximum yield of extracellular CGL was detected in the filtrates of Aspergillus carneus (6.29 U/mg) followed by A. ochraceous (6.03 U/ $\mathrm{mg})$, A. versicolor $(2.51 \mathrm{U} / \mathrm{mg})$, A. candidus $(2.1 \mathrm{U} / \mathrm{mg})$, A. niveus $(2.09 \mathrm{U} / \mathrm{mg})$, Penicillium sp (2.0 U/mg), Humicola sp (1.27 U/mg) and Stachybotryus sp (1.2 U/ $\mathrm{mg}$ ). In contrary, a quite lower activity of CGL was detected for Fusarium sp, Alternaria sp, A. oryzae and A. niger. Aspergillus was the most frequent genus displaying a higher potency for CGL production, consistently as reported for PLPdependent enzymes [14, 32]. The higher productivity of CGL by the various species of Aspergillus reveals their metabolomic identity for production of unique enzymatic system for assimilation of cystathionine. 
Table 1

Screening for cystathionine $\gamma$-lyase production from filamentous fungi

\begin{tabular}{|c|c|c|c|c|}
\hline No. & Fungal isolate & $\begin{array}{l}\text { Protein } \\
(\mathrm{mg} / \mathrm{ml})\end{array}$ & $\begin{array}{c}\text { Activity } \\
(\mathrm{U} / \mathrm{ml})\end{array}$ & $\begin{array}{l}\text { Specific activity } \\
(\mathrm{U} / \mathrm{mg})\end{array}$ \\
\hline 1 & Aspergillus awamori & $1.485 \pm 0.132$ & $0.85 \pm 0.26$ & 0.57 \\
\hline 2 & A. candidus & $1.352 \pm 0.066$ & $2.87 \pm 0.37$ & 2.12 \\
\hline 3 & A. carneus & $0.957 \pm 0.066$ & $6.02 \pm 0.3$ & 6.29 \\
\hline 4 & A. flavus 1 & $1.151 \pm 0.066$ & $2.28 \pm 0.09$ & 1.97 \\
\hline 5 & A. flavus link & $0.992 \pm 0.165$ & $1.47 \pm 0.095$ & 1.48 \\
\hline 6 & A. fumigatus & $1.324 \pm 0.231$ & $1.22 \pm 0.052$ & 0.92 \\
\hline 7 & A. flavipes & $0.924 \pm 0.099$ & $1.94 \pm 0.30$ & 2.09 \\
\hline 8 & A. niveus & $1.023 \pm 0.066$ & $1.4 \pm 0.36$ & 2.00 \\
\hline 9 & A. tamarii & $1.912 \pm 0.132$ & $1.58 \pm 0.2$ & 0.82 \\
\hline 10 & A. oryzae & $2.013 \pm 0.231$ & $1.94 \pm 0.25$ & 0.96 \\
\hline 11 & A. ochraceous & $0.891 \pm 0.099$ & $6.27 \pm 0.25$ & 6.03 \\
\hline 12 & A. sparsus & $1.324 \pm 0.165$ & $1.43 \pm 0.29$ & 1.08 \\
\hline 13 & A. versicolor & $0.561 \pm 0.165$ & $1.41 \pm 0.42$ & 2.51 \\
\hline 14 & Alternaria alternata & $1.353 \pm 0.198$ & $0.84 \pm 0.077$ & 0.62 \\
\hline 15 & Colletotrichum sp & $0.662 \pm 0.066$ & $0.99 \pm 0.12$ & 1.50 \\
\hline 16 & Humicola sp & $1.254 \pm 0.625$ & $1.6 \pm 0.244$ & 1.27 \\
\hline 17 & Fusarium oxysporum & $1.345 \pm 0.066$ & $1.27 \pm 0.16$ & 0.91 \\
\hline 18 & Fusarium moniliforme & $1.518 \pm 0.066$ & $1.38 \pm 0.31$ & 0.90 \\
\hline 19 & Fusarium sp & $1.353 \pm 0.132$ & $0.35 \pm 0.097$ & 0.03 \\
\hline 20 & Penicillium notatum & $0.792 \pm 0.132$ & $1.31 \pm 0.14$ & 2.00 \\
\hline 21 & Penicillium sp & $1.321 \pm 0.264$ & $3.41 \pm 0.37$ & 1.08 \\
\hline 22 & Stachybotyrs atra Corda & $1.287 \pm 0.264$ & $1.72 \pm 0.21$ & 1.33 \\
\hline
\end{tabular}

\section{Morphological description of the potent fungal isolates producing CGL}

The microscopical features of the potent CGL producing fungi were observed on Czapek's and malt extract agar medium according to the identification keys.

The highest CGL producer, Aspergillus sp, appeared as pale yellow-tan colonies with rapidly obvious growth on Czapek's agar (Fig. 1). The colony color was white at first then turned to vinaceous, reverse of yellow to red-brown shades with no exudates. Loosely columnar to hemispherical conidial heads, strigma was biserriate covers the upper third to half of the vesicle. On malt extract agar, the colonies have heavy sporulation, with deep vinaceous fawn color. The morphological characteristics of the current isolate of Aspergillus sp were typically the same as the phenotypic features of A. carnues (Van Tieghem) [11, 33, 44]. 

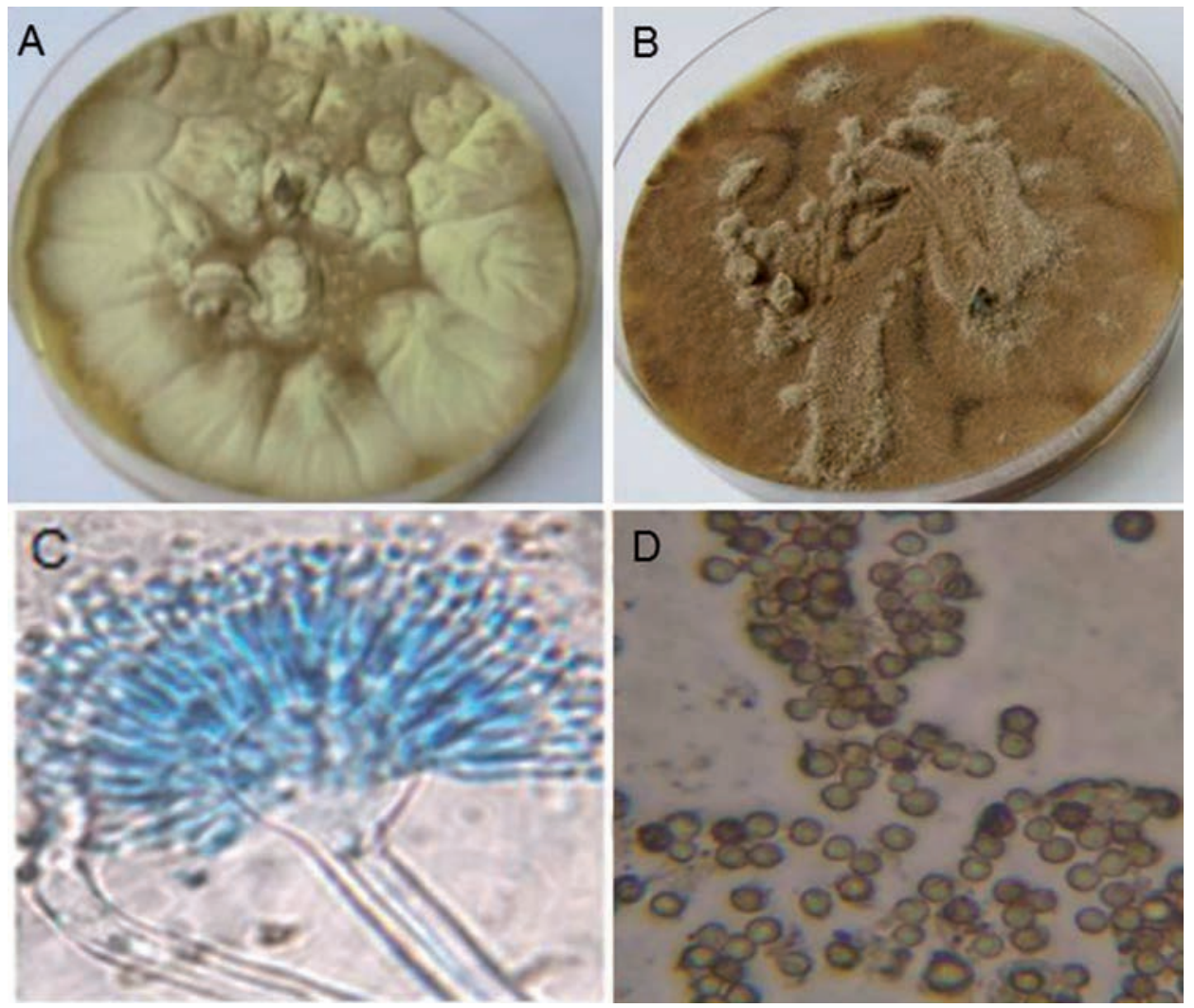

Fig. 1. Macro and micro-morphological features of Aspergillus carneus. Colonies of 4 days on Czapek's (A), malt extract (B) agar medium, conidia under light microscope 1000× (C), and conidia by light microscope $1000 \times(\mathrm{D})$

Aspergillus sp2 colonies were grown slightly on Czapek's agar, showing tough basal submerged mycelium with dull yellow-orange, crowded conidial structure, with persistent color near light yellow ocher (data not shown). The plate reverse was in yellowish-greenish, reddish, with abundant pale pink sclerotia. Conidial heads were globose in young, adhering to compact columns in age colonies. Strigmata were biserriate covering the entire vesicle. On malt extract agar, the isolate was grown rapidly, heavily submerged vegetative mycelium, few number of sclerotia. The morphological features of the isolate were consistent with those of A. ochraceus Wilhelm [11, 44].

Aspergillus sp3 colonies were grown slowly at Czapek's agar, white at first, passing through shades of yellow, orange-yellow to pea green, with no exudates. Reverse of the plates was purple-red. Conidial heads are hemispherical, radiate, spherical vesicle (data not shown). Strigmata were biserriate, globose conidia, with no appearance of sexual and asexual fruiting bodies. Colonies on malt extract agar grew rap- 
idly, displaying heavy sporulation with dense conidial heads, without exudates. The morphological description is identical to A. versicolor (Vuill. Tirabosci) [44].

Aspergillus sp4 isolate grew slowly on Czapek's agar with persistently white, with black sclerotia (data not shown). The reverse of the colonies was blackish purple, without exudates. Conidial heads were white-creamy color, globose at first then turned to loosely columnar, globose vesicle of typically fertile surface. Strigmata were uniserriate, then turned to persistently biserriate. Colonies on malt extract grew rapidly, heavy sporulation of white color, yellowish reverse, lacking to surface exudate. The morphological description typically follows A. candidus Link [44].

Aspergillus sp5 isolate grew slowly on Czapek's agar, showing white-yellow mycelium, radially furrowed, dense felt of mycelium centrally, with thinning towards the margin (data not shown). Reverse of colonies was dark-yellow to brown. Conidial heads were white to dull ivory, with biserriate strigmata, hemi-spherical vesicles. This description is identical to A. niveus Blochwitz [44].

Penicillium sp isolate grew rapidly on Czapek's agar, abundant conidial structure, azonate, with conspicuous radial furrows, heavily sporing, with white to yellowish margin (data not shown). Colony color was blue-green, with exudates, the reverse was yellow to golden yellow. Penicilli are biverticilate, metulae bearing cluster of strigma, conidia are golobse to sub-globose. On malt extract agar, the colonies grew more rapidly, velvety appearance, heavily sporing, slight darker shades, yellowish exudates, much furrowed pattern. The morphological description was closely identical to $P$. notatum Westling according to Pitt [42].

\section{Molecular characterization of A. carneus}

The morphologically identified A. carneus, as potent CGL producer, was further characterized based on the sequence of rDNA. After extraction and purification of genomic DNA from the fungal isolate, their purity was checked on $1 \%$ agarose gel. The gDNA was used as template for rDNA amplification using the primers Fw 18s rDNA and Rev 28s rDNA (Materials and Methods). After PCR running and agarose gel, the PCR amplicon was $526 \mathrm{bp}$ for the A. carneus (Fig. 2A). The PCR product of $A$. carneus was purified, sequenced and the retrieved sequence was deposited on Genbank KF723837. The retrieved sequence of A. carneus was blasted using multiple sequence alignment softwares, displaying more than $95 \%$ identities with the already deposited isolates of A. carneus EF669581.1, A. carneus EF669611.1, A. carneus EF669590.1 (E values zero and query coverage 98\%), while displaying a 97\% similarity with A. carneus FJ531203.1 and A. carneus FJ531202.1 (E values zero and query coverage $88 \%$ ) (Table 2). From the phylogenetic tree (Fig. 2B), the target sequence of rDNA of $A$. carneus display a strong similarity with various isolates of A. carneus deposited on the database, approving their genomic proximity with those of $A$. carneus. Interestingly, the molecular analysis based on rDNA sequence of A. carneus strongly ensures the morphological description of Raper and 


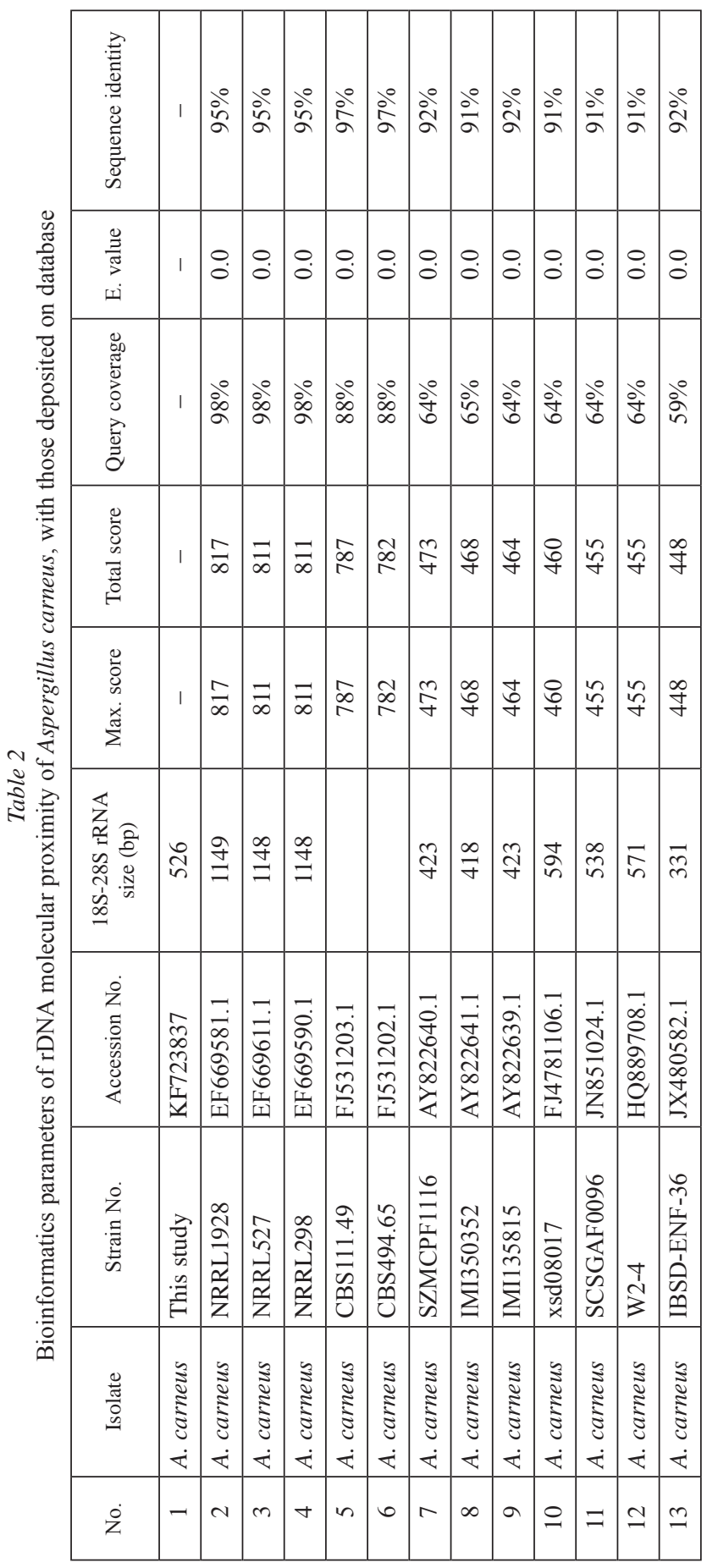

Acta Biologica Hungarica 66, 2015 


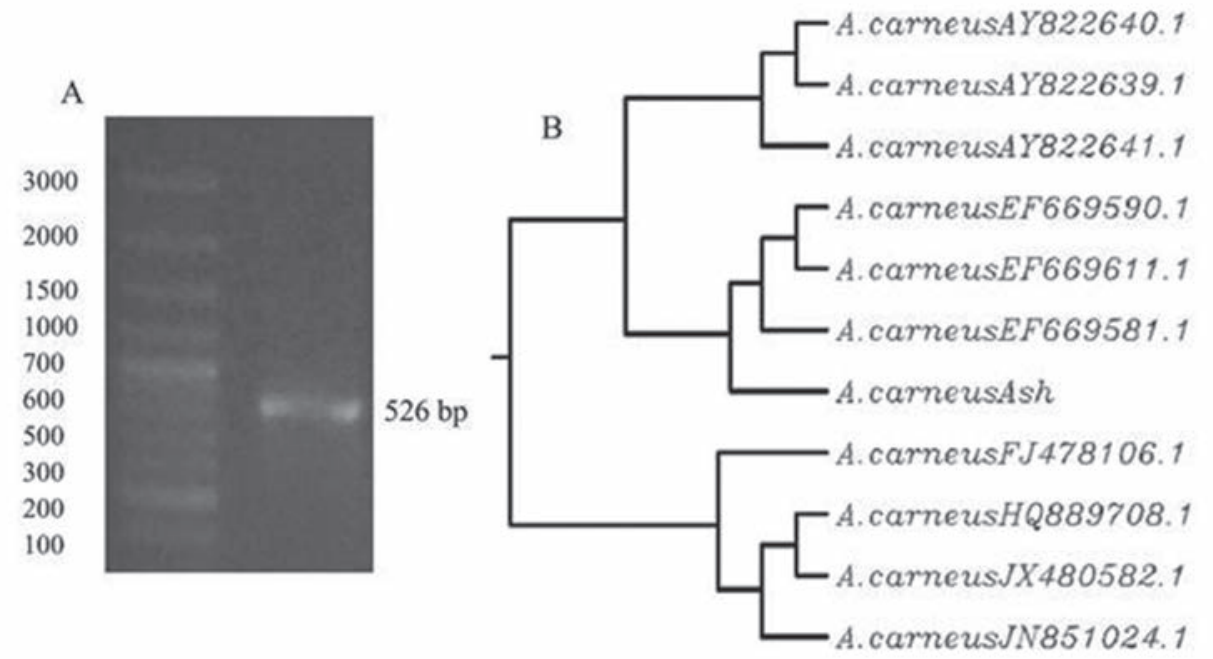

Fig. 2. PCR product of $18 \mathrm{~S}-28 \mathrm{~S}$ rDNA (A), and dendrogramme (B) of A. carneus. DNA ladder of 100 bp (Solis BioDyne, Riia 185a, 51014 Tartu, Estonia) was used

Fennell [40] and Domsch et al. [10]. Molecularly, the complete sequence of ITS15.8S-ITS2 regions was the most reliable approach for identification of fungi $[4,12$, 23]. The ITS regions were frequently used for identification of various species of Aspergillus $[6,7,19,28]$. The sequence of $18 \mathrm{~S}-28 \mathrm{~S}$ rDNA region flanking the ITS domains and 5.8S rDNA for identification of fungi was designated as a most reliable tool for intra-species discrimination of Aspergilli [7, 14, 31, 27]. Thus, regarding potency for CGL yield, the yield of the enzyme underwent maximization by optimization of the nutritional and physical traits.

\section{Influence of medium sulfur starvation on the yield of CGL by A. carneus}

The effect of sulfur starvation on the productivity of CGL and intracellular thiols by A. carneus was assessed. After two days of incubation of A. carneus on sulfur-free basal medium, the cultures were sub-cultured to standard L-methionine containing medium, incubated for 10 days at $30^{\circ} \mathrm{C}$, on shaker incubator $120 \mathrm{rpm}$. The activity of intra- and extracellular CGL, L-methionine uptake and concentration of intracellular thiols were determined. From the growth and CGL productivity of A. carneus (Fig. 3), the intra- and extracellular CGL activity was increased sequentially with the incubation time, till maximum values 4.3 and $10.5 \mathrm{U} / \mathrm{mg}$, respectively by the $5^{\text {th }}$ days, followed by an obvious decrease on their activities with the time. Upon sulfur starvation, the activity of extracellular CGL by A. carneus was increased by 1.7 -fold, comparing to non-sulfur starved cultures, and by 4.1 -fold regarding to L-methionine free medium. The activity of extra- and intracellular CGL upon growing of $A$. carneus on 


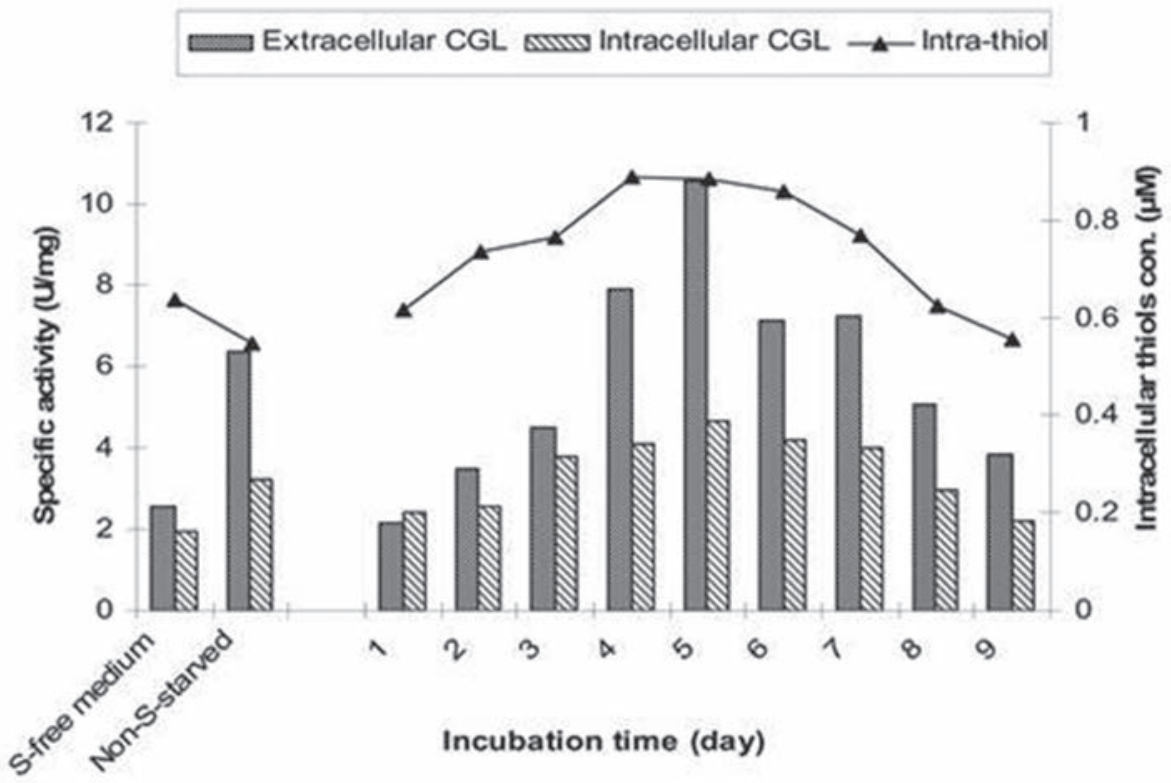

Fig. 3. Kinetics of sulfur starvation on intra- and extracellular CGL productivity and intracellular pool of thiols

L-methionine free medium was 2.4 and $1.7 \mathrm{U} / \mathrm{mg}$, respectively, ensuring the independence of CGL on sulfur amino acids and constitutive identity of this enzyme. For sulfur starved cultures, the residual concentration of L-methionine was strongly reduced, comparing to non-sulfur starved cultures of $A$. carneus, assuming the activation of specific L-methionine transporters across the plasma membrane, overexpressing CGL. Similar results approving the over-expression of CGL by sulfur starvation have been described for homocysteine $\gamma$-lyase [14]. Also, from these results, the activity of intracellular glutamate dehydrogenase was shown to increase substantially with the incubation time, justifying their induction to scavenger the extra ammonia to form amino acids from corresponding keto acids [14]. Similarly, the uptake of L-methionine and induction of L-methioninase by P. chrysogenum was increased by ten-folds upon sulfur starvation comparing to non-starved cultures, as revealed from the $\mathrm{Km}$ values [2]. From the results, the concentration of extracellular thiols was contrary to levels of intracellular ones, assuming the assimilation of methionine with various metabolic pathways as protein synthesis, DNA regulation, polyamines synthesis as reviewed by El-Sayed [16]. Consistently, upon sulfur starvation, the activity of phosphosulfate reductase by Laccaria biocolor, a key enzyme of sulfate assimilation was significantly increased, however, after addition of glutathione, the enzyme activity was decreased, revealing the uncoupling of sulfur uptake [37]. Coincidently, the inductive regulation of acid protease by the medium nitrogen and sulfur for Botrytis cinerea was observed [46]. 


\section{Effect of gamma rays irradiation of $\mathrm{A}$. carneus on the productivity of CGL}

The effect of $\gamma$-irradiation ( 0.5 to $10.0 \mathrm{kGy}$ for $10 \mathrm{~min}$ ) of $A$. carneus on the productivity of CGL was assessed. The slants of 5 days age were irradiated by Indian gamma cell of Co-60 (Egyptian Atomic Energy Authority, Inshas, Egypt). The irradiated and non-irradiated spores were sub-cultured to solid medium and the morphological deformation of the developed fungal colonies, as well as, the activity of intra- and extracellular CGL was assessed.

From the morphological features (Fig. 4), apparently A. carneus was not affected by doses $0.5-1.0 \mathrm{kGy}$ of $\gamma$-rays, with an obvious morphological deformation and inhibition of fungal viability with the further irradiation doses. While, a complete inhibition on the fungal growth was observed at 8 to $10 \mathrm{kGy}$, with calculated $\mathrm{D}_{10}$ values $4.5 \mathrm{kGy}$ (data not shown). The toxicity of ionizing radiation to fungi has frequently been reported with $\mathrm{D}_{10}$ values in the range 4 to $8 \mathrm{kGy}[1,24]$.

The maximum yield of CGL (Fig. 5) by A. carneus was obtained using $2.0 \mathrm{kGy}$ of $\gamma$-rays, with about two fold increases, comparing to control (non-irradiated spores). However, with further doses of $\gamma$-rays, the enzyme activity was strongly repressed, parallel to viability. The response of intra- and extracellular A. carneus CGLs was relatively similar. In partially consistence, the yield of cellulase by Cellulomonas biazotea [43], Trichoderma resssei [35] and Acremonium cellulolyticus [21] was obviously increased, upon gamma irradiation at $0.5 \mathrm{kGy}$.
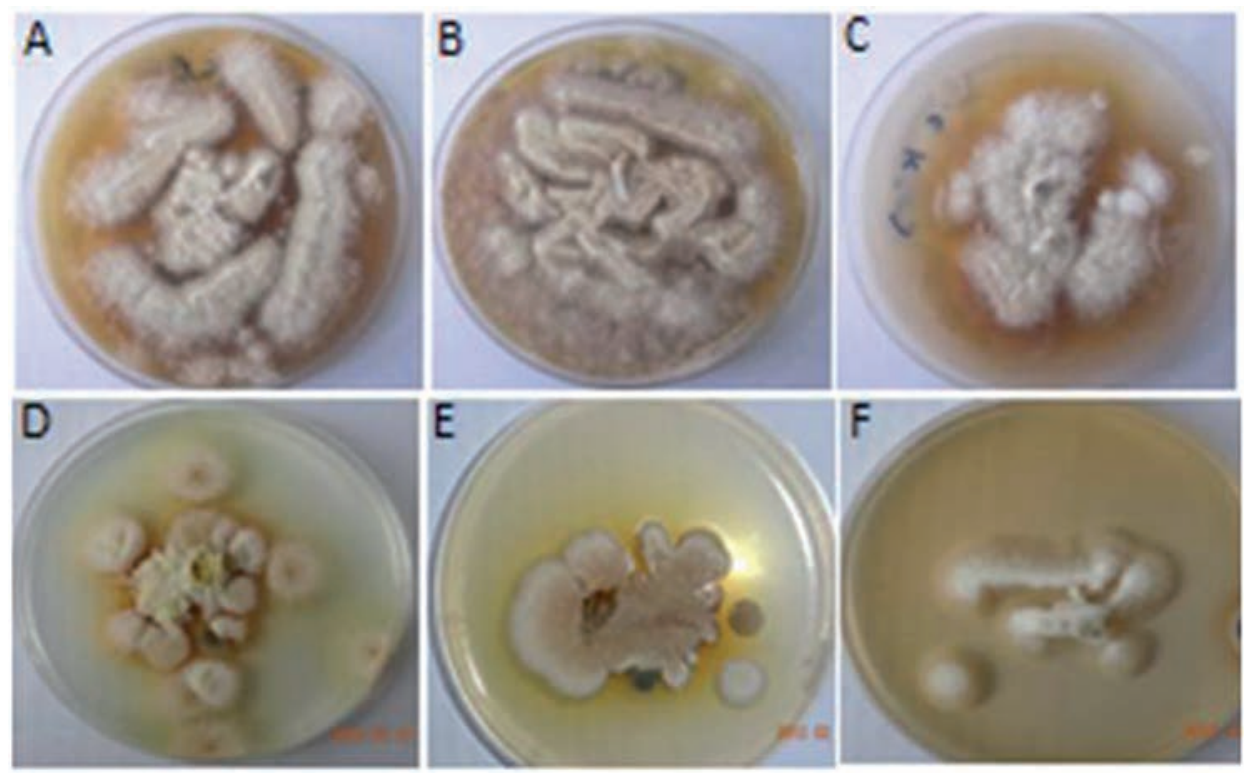

Fig. 4. Viability of A. carneus upon irradiation by gamma rays with zero dose (A), $0.5 \mathrm{kGy}$ (B), $1.0 \mathrm{kGy}(\mathrm{C}), 2.0 \mathrm{kGy}(\mathrm{D}), 4.0 \mathrm{kGy}(\mathrm{E})$ and $8.0 \mathrm{kGy}(\mathrm{F})$, for $10 \mathrm{~min}$ 


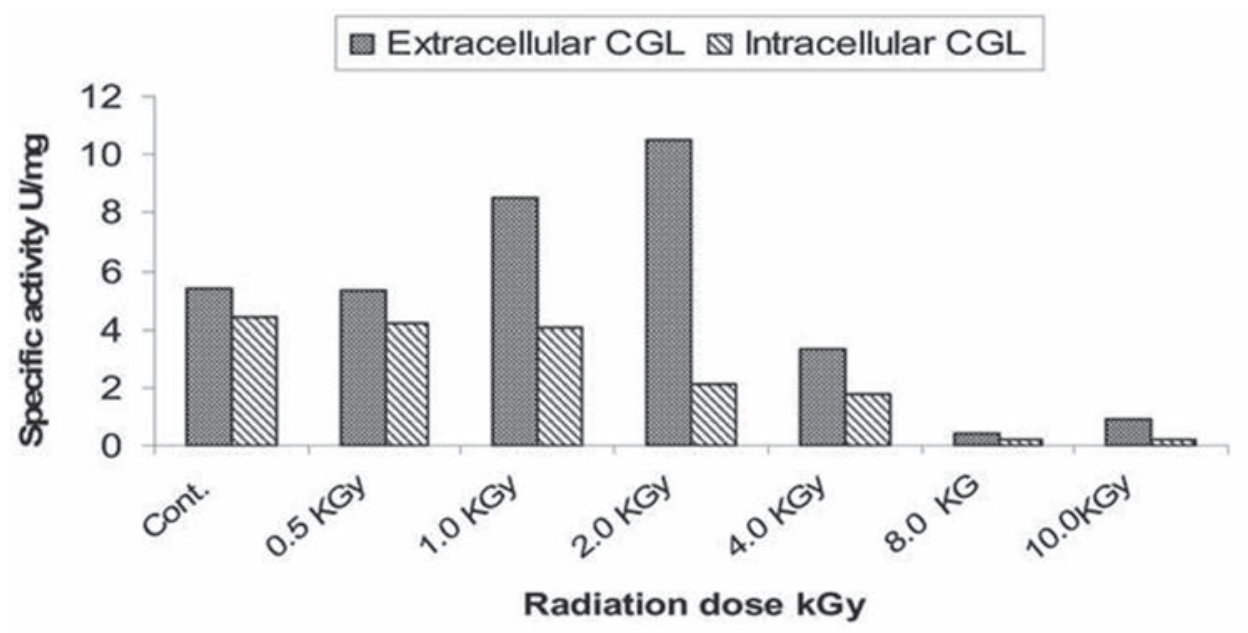

Fig. 5. Over-induction of $A$. carneus CGL by gamma rays irradiation

In conclusion, the potency for CGL production from the isolated filamentous fungi was assessed. A. carneus KF723837displayed the highest intra- and extracellular CGL yield, extensively studied based on morphological, biochemical and molecular traits. Upon sulfur starvation, the yield of CGL was increased by two-fold, as well as L-methionine uptake, intracellular thiols and activity of glutamate dehydrogenase was strongly increased, regarding to control. Also, the activity of CGL by A. carneus was strongly induced upon $\gamma$-irradiation of the fungal spores at $0.2 \mathrm{kGy}$ for $10 \mathrm{~min}$. Further biochemical and molecular characterization of CGL from A. carneus is undergoing, to explore its catalytic and structural identity.

\section{REFERENCES}

1. Aziz, N.H., Mahrous, S. R. (2004) Effect of $\gamma$-irradiation on aflatoxin $\mathrm{B}_{1}$ production by A. flavus and chemical composition of three crop seeds. Nahrung-Food, 48, 234-238.

2. Benko, P. V., Wood, T. C., Segel, I. H. (1967) Specificity and regulation of the methionine transport in filamentous fungi. Arch. Biochem. Biophys. 122, 783-804.

3. Booth, C. (1971) The Genus Fusarium. Commonwealth Mycological Institute, Lincoln, LIN, United Kingdom.

4. Boysen, M. E., Jacobsson, K.-G., Schnurer, J. (2000) Molecular identification of species from the Penicillium requeforti group associated with spoiled animal feed. Appl. Environ. Micobiol. 66, $1525-1526$.

5. Bruinenberg, P. G., De Roou, G., Limsowtin, G. (1997) Purification and characterization of cystathionine gamma lyase from Lactococcus lactis cremoris SK11: possible role in flavor compound formation during cheese maturation. Appl. Environ. Microbiol. 63, 561-566.

6. Chen, S. C. A., Halliday, C. L., Meyer, W. (2002) A review of nucleic acid-based diagnostic tests for systemic mycoses with an emphasis on polymerase chain reaction-based assays. Med. Mycol. 40, $333-357$. 
7. De-Aguirre, L., Hurst, S. F., Choi, J. S., Shin, J. H., Hinrikson, H. P., Morrison, C. J. (2004) Rapid differentiation of Aspergillus species from other medically important opportunistic molds and yeasts by PCR-enzyme immunoassay. J. Clin. Microbiol. 42, 3495-3504.

8. De Angelis, M., Curtin, A. C., Mac Sweeney, P., Faccia, M., Gobbetti, M. (2002) Lactobacillus reuteri DSM 20016: purification and characterization of cystathionine gamma lyase and use as adjunct starter in cheese making. J. Dairy Res. 69, 255-267.

9. Delavier-Klutchko, C., Flavin, M. (1965) Enzymatic synthesis and cleavage of cystathionine in fungi and bacteria. J. Biol. Chem. 240, 2537-2549.

10. Domsch, K. H., Gams, W., Anderson, T. (1980) Compendium of Soil Fungi. Academic Press. IHW Verlag, Eching, Germany.

11. Domsch, K. H., Gams, W., Anderson, T. (2007) Compendium of Soil Fungi. 2nd Edition. IHW Verlag, Eching, Germany

12. Dupont, J., Magnin, S., Marti, A., Brousse, M. (1999) Molecular tools for identification of Penicillium starter cultures used in food industry. Int. J. Food Microbiol. 49, 109-118.

13. Ellis, M. B. (1971) Dematiaceous Hyphomycetes. Commonwealth Mycological Institute, Kew, Surrey, England.

14. El-Sayed, A. S. A., Khalaf, S. A., Aziz, H. A. (2013) Characterization of homocysteine $\gamma$-lyase from submerged and solid cultures of Aspergillus fumigatus ASH (JX006238). J. Microbiol. Biotechnol. 23, 499-510.

15. El-Sayed, A. S. A. (2009) L-Methioninase production by Aspergillus flavipes under solid-state fermentation. J. Basic Microbiol. 49, 331-341.

16. El-Sayed, A. S. A. (2010) Microbial L-methioninase, molecular characterization and therapeutic applications. Appl. Microbiol. Biotechnol. 86, 445-467.

17. El-Sayed, A. S. A. (2011) Purification and characterization of a new L-methioninase from Aspergillus flavipes under solid state fermentation. J. Microbiol. 49, 130-140.

18. El-Sayed, A. S. A., Shindia, A. A., Zaher, Y. (2012) L-Amino acid oxidase from filamentous fungi: screening and optimization. Ann. Microbiol. 62, 773-784.

19. Endres, W., Wuttge, B. (1978) Occurrence of secondary cystathioninuria in children with inherited metabolic disorders, liver diseases, neoplasms, cystic fibrosis and celiac disease. Eur. J. Pediatr. 129, $29-35$.

20. Fang, X., Yano, S., Inoue, H., Sawayama, S. (2009) Strain improvement of Acremonium cellulolyticus for cellulase production by mutation. J. Biosci. Bioeng. 107, 256-261.

21. Flavin, M. (1975) Metabolism of Sulfur Compounds. Academic Press, New York.

22. Florez, A. B., Alvarez-Martin, P., Lopez-Diaz, T. M. Mayo, B. (2007) Morphotypic and molecular identification of filamentous fungi from Spanish blue-veined cabrales cheese, and typing of Penicillium requeforti and Geotrichum candidum isolates. Inter. Dairy J. 17, 350-357.

23. Gadgil, N. J., Daginawala, H. F., Chakakrabarti, T., Khanna, P. (1995) Enhanced cellulase production by mutant of Trichoderma reesei. Enzyme Microb. Technol. 17, 942-946.

24. Gente, S., La Carbona, S. Guéguen, M. (2007) Levels of cystathionine $\gamma$-lyase production by Geotrichum candidum in synthetic media and correlation with the presence of sulphur flavours in cheese. Int. J. Food Microbiol. 114, 136-142.

25. Harris, H., Penrose, L. S., Thomas, D. H. H. (1959) Cystathioninuria. Ann. Hum. Genet. 23, 442-453.

26. Henry, T., Iwen, P. C., Hinrichs, S. H. (2000) Identification of Aspergillus species using internal transcribed spacer regions 1 and 2. J. Clin. Microbiol. 38, 1510-1515.

27. Hiraishi, H., Tsuyoshi Miyake, T., Ono, B. I. (2008) Transcriptional regulation of Saccharomyces cerevisiae CYS3 encoding cystathionine $\gamma$-lyase, Curr. Genet. 53, 225-234.

28. Irmler, S., Raboud, S., Beisert, B., Rauhut, D., Berthoud, H. (2008) Cloning and characterization of two Lactobacillus casei genes encoding a cystathionine lyase. Appl. Environ. Microbiol. 74, 99.

29. Kebeish, R., El-Sayed, A. S. A. (2012) Morphological and molecular characterization of L-methioninase producing Aspergillus species. Af. J. Microbiol. 11, 15280-15290.

30. Khalaf, S., El-Sayed, A. S. A. (2009) L-Methioninase production by filamentous fungi: screening and optimization under submerged conditions. Curr. Microbiol. 58, 219-226. 
31. Klich, M. A., Pitt, J. I. (1992) A Laboratory Guide to the Common Aspergillus Species and their Teleomorphs. Common Wealth Scientific and Industrial Research Organization, Division of Food Processing, North Ryde, Australia.

32. Latifian, M., Hamidin-Esfahani, Z., Barzegar, M. (2007) Evaluation of culture conditions for cellulos production by two Trichoderma reesei mutants under solid-state fermentation conditions. Bioresour. Technol. 98, 1-4.

33. Lowry, O. H., Rosenrough, N. J., Farr, A. L., Randall, R. J. (1951) Protein measurement with the Folin phenol reagent. J. Biol. Chem. 193, 265-275.

34. Mansouri-Bauly, H., Sýkorová, Z., Scheerer, U., Kopriva, S. (2006) Sulfur uptake in the ectomycorrhizal fungus Laccaria bicolor S238N. Mycorrhiza 16, 421-427.

35. Nagasawa, T., Kansaki, H., Yamada, H. (1984) Cystathionine $\gamma$-lyase of Streptomyces phaeochromogenes. J. Biol. Chem. 259, 10393-10403.

36. Paszewski, A., Grabski, J. (1973) Studies on $\beta$-cystathionase and O-acetylhomoserine sulfhydrylase as the enzymes of alternative methionine biosynthetic pathways. Acta Biochim. Pol. 20, 159-168.

37. Perry, T. L., Robinson, G. C., Teasdale, J. M., Hansen, S. (1967) Concurrence of cystathioninuria, nephrogenic diabetes insipidus and severe anemia. N. Engl. J. Med. 276, 721-725.

38. Pitt, Q. W. (1979) The Genus Penicillium and its Teleomorphic States Eupenicillium and Talaromyces. Academic Press, London.

39. Rajoka, M. I. (2005) Double mutants of Cellulomonas biazotea for production of cellulases and hemicellulases following growth on straw of a perennial grass. World J. Microbiol. Biotechnol. 21, 1063-1066.

40. Raper, K. B., Fennell, D. I. (1965) The Genus Aspergillus. The Williams and Wilkins Company, Baltimore.

41. Rifai, M. A. (1969) A Revision of the Genus Trichoderma. Commonwealth Mycological Institute, Kew.

42. Rolland, S. G., Bruel, C. A. (2008) Sulfur and nitrogen regulation of the protease-encoding ACP1 gene in the fungus Botrytis cinerea: correlation with a phospholipase D activity. Microbiology 154, 1464-1473.

43. Smacchi, E., Gobbetti, M. (1998) Purification and characterization of cystathionine gamma lyase from Lactobacillus fermentum DT41. FEMS Microbiol. Lett. 166, 197-202.

44. Uren, J. R. (1987) Cystathionine $\gamma$-lyase from Escherichia coli. Methods Enzymol. 143, 483-486

45. Yang, G. (2011) Hydrogen sulfide in cell survival: a double-edged sword. Expert Rev. Clin Pharmacol. 4, 33-47.

46. Yang, G., Wu, L., Bryan, S., Khaper, N., Mani, S. Wang, R. (2010) Cystathionine gamma-lyase deficiency and overproliferation of smooth muscle cells. Cardiovasc Res. 86, 487-495. 